J. Lake Sci. (湖泊科学), 2020, 32(4): 1100-1115

DOI 10. $18307 / 2020.0418$

(c) 2020 by Journal of Lake Sciences

\title{
乌梁素海沉水植物群落光谱特征及冠层水深影响分析
}

\author{
杜雨春子 ${ }^{1}$, 青 松 $^{1 * *}$, 曹萌萌 ${ }^{1}$, 袁瑞强 ${ }^{1}$, 顺布 日 $^{1}$, 郝艳玲 ${ }^{2}$ \\ (1: 内蒙古师范大学地理科学学院, 呼和浩特 010022) \\ (2: 内蒙古大学生态与环境学院, 呼和浩特 010021)
}

\begin{abstract}
摘 要: 沉水植物对于改善富营养化水体和重建水生生态系统起着至关重要的作用. 应用遥感技术可以实时、大面积监 测沉水植物的分布和生长情况, 而冠层水深直接影响沉水植物在湖泊、河流中的准确遥感解译. 本研究基于实测光谱数 据, 分析了乌梁素海沉水植物光谱特征, 并研究了冠层水深对乌梁素海沉水植物反射光谱的影响, 建立了乌梁素海沉水 植物冠层水深反演模型. 结果表明: 1) 挺水植物在短波红外 $1662 \mathrm{~nm}$ 和 $2223 \mathrm{~nm}$ 附近分别有一个反射峰, 这是挺水植物区 别于沉水植物和漂浮藻类的重要波段; 0 深度沉水植物 $(W D C=0)$ 与漂浮藻类的光谱反射率非常接近, 但是在绿波段 (550 690 nm) 有明显差异, 因此,可以利用绿波段和短波红外波段的光谱特征来区分挺水植物、沉水植物和漂浮藻类. 2) 沉水植物群落的光谱反射率随冠层水深的增加而降低, 在 700 900 nm 波段范围内变化最为明显, 且在 700 735 nm 波 段附近, 沉水植物群落光谱反射率与冠层水深呈显著负相关. 3) 在建立的单波段/波段比沉水植物冠层水深反演模型中, 波段比反演模型要优于单波段反演模型, 波段比反演模型的决定系数 $R^{2}>0.70$, 均方根误差 $<13.70 \mathrm{~cm}$, 平均相对误差 $<$ $28 \%$, 反演精度较好, 适用于 $10 \sim 60 \mathrm{~cm}$ 沉水植物冠层水深的反演. 4) 利用波段响应函数, 将实测光谱反射率积分到 Landsat-8 OLI 波段上, 建立 OLI 了冠层水深反演模型, 其中, 波段比幂函数模型反演效果最好, $R^{2}$ 为 0.49 , 均方根误差为 $18.17 \mathrm{~cm}$, 平均相对误差 $40.05 \%$. 可用于精确大气校正后乌梁素海沉水植物冠层水深的反演.
\end{abstract}

关键词: 沉水植物; 光谱反射率;冠层水深;相关分析;回归模型;乌梁素海

\section{Spectral features of submerged aquatic vegetation and water depths impact in Lake Ulan- suhai $^{*}$}

DU Yuchunzi ${ }^{1}$, QING Song ${ }^{1 * *}$, CAO Mengmeng ${ }^{1}$, YUAN Ruiqiang ${ }^{1}$, SHUN Buri ${ }^{1} \&$ HAO Yanling ${ }^{2}$

(1: College of Geographical Science, Inner Mongolia Normal University, Hohhot 010022, P.R.China)

(2: School of Ecology and Environment, Inner Mongolia University, Hohhot 010021, P.R.China)

Abstract: Submerged plants play an important role in improving eutrophic water and rebuilding aquatic ecosystem. Using remote sensing technology, the distribution and growth of submerged plants can be monitored in real time and in large area. The depth from the water surface to the plant canopy $(W D C)$ directly affects the accurate remote sensing interpretation of submerged plants in lakes and rivers. Based on the measured spectral data, the spectral characteristics of submerged aquatic vegetation in Lake Ulansuhai were analyzed, and the effects of canopy water depth on the reflectance spectra of submerged plants in Lake Ulansuhai were studied. The retrieval model of canopy water depth of submerged plants in Lake Ulansuhai was established. The results showed that 1 ) There is a reflection peak near the $1662 \mathrm{~nm}$ and $2223 \mathrm{~nm}$ of the short wave infrared of the emergent plants, which is an important band that distinguishes the emergent plants from the submerged plants and the floating algae. The spectral reflectance of the submerged plants $(W D C=0)$ and the floating algae is very close, but there are obvious differences in the green band (550-690 nm) . Therefore, the spectral characteristics of the green band and the short wave infrared band can be used to distinguish emergent plants, submerged plants and floating algae. 2) The spectral reflectance of submerged plant community decreased with the increase of $W D C$, and it changed most obviously in the range of 700-900 nm, and there was a significant negative correlation between the

* 2019-09-04 收稿;2019-11-30 收修改稿.

国家自然科学基金项目 (41961057，61461034)、内蒙古自治区高等学校青年科技英才支持计划项目 ( NJYT-17B04) 和内蒙古自然科学基金项目(2019MS04013)联合资助.

** 通信作者;E-mail: qingsong@imnu.edu.cn. 
spectral reflectance of submerged plant community and WDC near the range of 700-735 nm. 3) A single band / band ratio retrieval model of WDC is established, in which the band ratio retrieval model is better than the single band retrieval model. The $R^{2}$ of the band retrieval model is more than 0.70 , the $R M S E<13.70 \mathrm{~cm}$, the $M R P E<28 \%$, and the retrieval accuracy is high, which is suitable for retrieval of canopy water depth of submerged plants of 10-60 cm. 4) The situ spectral reflectance is integrated into the Landsat- 8 OLI band by using the spectral response function, and the retrieval model of the water depth of OLI is established. Among them, the power function model of band ratio has the best retrieval effect, the $R^{2}$ is 0.49 , the $R M S E$ is $18.17 \mathrm{~cm}$, the MRPE is $40.05 \%$, which can be used for the retrieval of the water depth of the submerged plant canopy in Lake Ulansuhai after accurate atmospheric correction.

Keywords: Submerged aquatic vegetation; spectral features; water depth; correlation analysis; regression model; Lake Ulansuhai

沉水植物在浅水湖泊湿地发挥着不可忽视的生态功能, 如吸收氮磷等富营养化物质, 抑制浮游植物生 长, 为无脊椎动物、鱼、水禽提供栖息地, 为浮游动物提供庇护所, 促进底层沉积物的淤积等. 因此实时监测 湖泊沉水植物,对于水资源调查研究、开发保护、水环境生态修复具有重要意义 ${ }^{[1-4]}$.

传统监测沉水植物分布与生长状况的现场调查法和潜水测量法耗时耗力、监测覆盖范围小, 而且影响 水体环境 ${ }^{[4]}$. 遥感技术能够大面积同步获取地物信息, 所以在水生植物时空分布监测方面具有传统方法不 可比拟的优势 ${ }^{[5]}$. 在多光谱应用方面, 许多学者利用 GF, Landsat 系列 (包括 MSS、TM、ETM+), SPOT 和 HJ$\mathrm{CCD}$ 等遥感数据对水生植物进行监测、初步分类, 提取和制图, 并获得了很好的研究结果 ${ }^{[6-9]}$; 其中, Dogan 等 ${ }^{[6]}$ 利用 Quickbird 卫星数据绘制了浅湖沉水植物覆盖范围, 并指出冠层水深是影响大规模遥感监测沉水 植物覆盖度和丰度的主要因素. Rotta 等 ${ }^{[10]}$ 探讨了利用 SPOT-6 估算内陆水域沉水植物高度 $(S A V)$ 的可行 性, 并指出在深度大于 $5 \mathrm{~m}$, 高度为 $1.5 \mathrm{~m}$ 的情况下, 沉水植物反射率的灵敏度低. 近几年来, 随着高光谱遥 感技术的应用与发展, 使遥感由定性分析向定量或半定量的转化成为可能, 高光谱遥感具有空间分辨率和 光谱分辨率高的特点 ${ }^{[11]}$. 目前, 国内外学者使用实测高光谱数据对内陆湖泊的沉水植物进行种类识别、分 类、覆盖度、生物量评估及沉水植物结构特征与光谱信息关系等方面的定量研究 ${ }^{[12-13]}$. Pande-Chhetri 等 ${ }^{[14]}$ 利 用机载 CASI 高光谱传感器, 对浅水湖泊 (深度 $<3 \mathrm{~m}$ ) 沉水植物进行了遥感分类. Zou 等 ${ }^{[15]}$ 在富营养化湖中, 利用实测高光谱数据研究了覆盖度与沉水植物光谱特征之间的关系, 并指出沉水植物光谱反射率随覆盖度 的减少而下降, 水深是影响沉水植物覆盖度的主要因素. 由此可见水深这一重要因素一直以来直接影响着 沉水植物的遥感监测 ${ }^{[16-19]}$. 由于水体环境的复杂性, 目前对沉水植物光谱特征及沉水植物群落冠层在水下 深度 (冠层水深) 对沉水植物光谱影响的定量研究还需进一步深人探讨.

本文以内蒙古巴彦淖尔市境内乌梁素海沉水植物群落为研究对象, 基于地物光谱仪测定的沉水植物光谱 数据, 开展如下研究:1) 分析沉水植物与其他地类光谱特征差异; 2) 探讨冠层水深对沉水植物群落光谱特征 的影响; 3) 建立冠层水深遥感反演模型;4)利用 Landsat-8 OLI 数据反演得到乌梁素海冠层水深分布图.

\section{1 数据和方法}

\section{1 研究区概况}

乌梁素海 ( $40^{\circ} 36^{\prime} \sim 41^{\circ} 03^{\prime} \mathrm{N}, 108^{\circ} 43^{\prime} \sim 108^{\circ} 57^{\prime} \mathrm{E}$ ) (图 1) 位于内蒙古巴彦淖尔市境内, 是中国的八大淡 水湖之一, 也是河套灌区唯一的排涝湖. 湖泊呈南北长、东西窄的狭长形态, 湖岸线长 $130 \mathrm{~km}$. 湖泊蓄水量 2.5 亿 3 亿 $\mathrm{m}^{3}$, 水深为 $0.5 \sim 3.0 \mathrm{~m}$, 平均水深 $1.5 \mathrm{~m}$, 水域面积 $273.32 \mathrm{~km}^{2}$. 所在地区的多年平均气温为 $7.3^{\circ} \mathrm{C}$, 多年平均降雨量为 $224 \mathrm{~mm}$, 蒸发量为 $1502 \mathrm{~mm}$, 全年无霜期为 $152 \mathrm{~d}$, 湖水于每年 11 月初结冰, 次年 4 月份解冻, 冰封期为 5 个月. 乌梁素海还是横跨欧亚大陆鸟类栖息和迁移的重要场所, 是黄河中上游重要的 保水、蓄水和调水基地, 也是全球范围内荒漠半荒漠化地区极为少见的具有很高生态效益的大型多功能草 型湖泊, 是地球上同一纬度最大的自然湿地, 在中国湿地、荒漠及动物物种 3 大生态系统保护中均居于重要 地位. 由于长期受农田退水、工业废水等的影响, 湖水被严重污染, 湖区内挺水植物、沉水植物等大型水生植 物疯长, 导致乌梁素海成为重度富营养化草型湖泊 ${ }^{[20-23]}$.

乌梁素海水生植被生长茂盛, 在全湖范围内广泛分布, 植被种类大致可以分为挺水植被、沉水植被和漂 浮藻类 3 类. 其中, 挺水植被主要有芦苇、宽叶香蒲, 芦苇为优势种, 4 月开始发芽出青, 9 月份开始衰退枯 
黄, 挺水植物占湖面的 $1 / 2$, 主要分布在湖的中部、西岸和北部, 芦苇外围生长着少量香蒲, 面积不大; 沉水植 被有龙须眼子菜、菹草、狐尾藻、茨藻、轮藻、竹叶眼子菜等, 龙须眼子菜和穗花狐尾藻为沉水植被优势种, 5 月中旬开始萌芽, 10 月开始逐渐衰退, 主要分布在明水区, 但是南部明水区分布较少. 漂浮藻类主要为黄苔, 黄苔由水绵、双星藻、转板藻 3 个属的藻类组成, 其丝状绿藻最初生长于水下, 缠绕在沉水植被上、或依附在 底泥上生长, 当聚集到一定程度后会形成团块,随着光合作用产生的气泡飘浮并出露水面,受到强光照射部 分死亡而呈现出黄色,被称为“黄苔”, 5 月初“黄苔”开始出现, 7-8 月份“黄苔”大面积暴发,主要分布在中 部和东部 ${ }^{[24-26]}$.

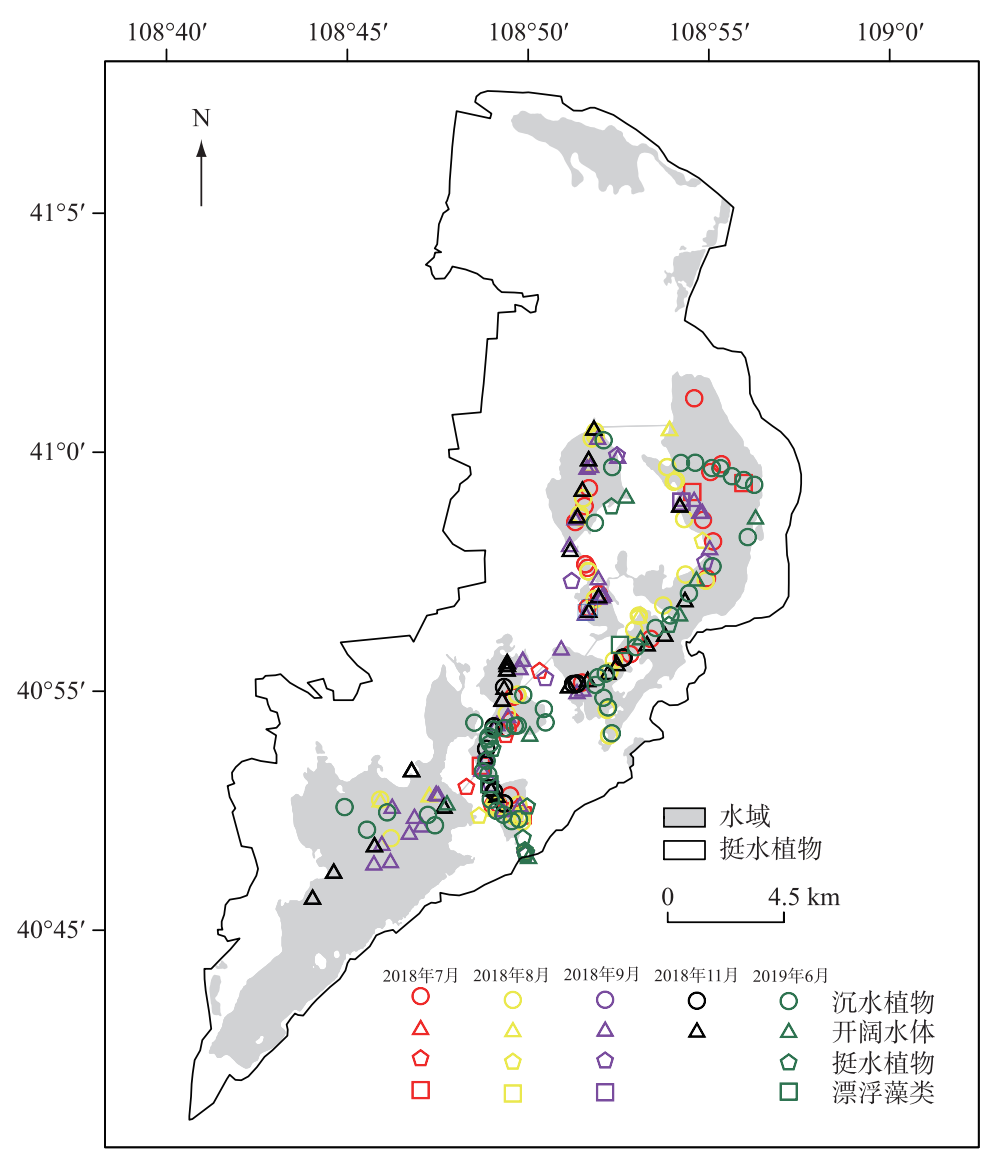

图 1 乌梁素海地理位置及实测站位

Fig. 1 Location of Lake Ulansuhai and the sampling sites

\section{2 野外实测}

本研究分别于 2018 年 7 月 16 日、 8 月 17 日、 9 月 2 日、 9 月 18 日、 11 月 5 日和 2019 年 6 月 17 日在乌梁 素海开展了 6 次为期 2 日的野外调查, 且时间与 Landsat- 8 卫星过境时间同步,共获得有效数据 378 组,包括 挺水植物 (30 组)、沉水植物 ( 228 组)、漂浮藻类 ( 8 组) 和开阔水体 (112 组) 的遥感反射率光谱、冠层水深/ 水深和现场照片 (图 1 和图 2).

光谱测量采用美国 ASD 公司生产的 ASD Field Spec 4 地物光谱仪, 其测量波段范围为 $350 \sim 2500 \mathrm{~nm}$, 光 谱分辨率为 $3 \mathrm{~nm}$, 光纤视场为 $25^{\circ}, 350 \sim 1000 \mathrm{~nm}$ 内采样间隔为 $1.4 \mathrm{~nm}, 1001 \sim 2500 \mathrm{~nm}$ 内采样间隔为 1.1 $\mathrm{nm}$. 光谱测量方法采用唐军武等提出的水面以上水体光谱测量方法 ${ }^{[27]}$. 遥感反射率测量在无风、天气晴朗 时进行, 且每个样点需要测量标准灰板、水体和天空光的辐射亮度, 剔除异常数据之后, 取均值作为该点的 光谱数据. 为了避开水体对太阳直射反射和船体阴影等影响, 需要采用一定的观测角度, 仪器观测平面与太 
阳人射平面夹角为 $90 \sim 145^{\circ}$ 之间, 且仪器与水体之间的距离为 $1 \mathrm{~m}$. 用卷尺现场测量站点沉水植物群落从水 面到植物冠层的深度, 即冠层水深 (WDC). 冠层水深呈正态分布, 其平均值和标准差分别为 42.73 和 25.00 $\mathrm{cm}$. 用塞氏盘测量水体透明度, 利用手持 GPS 定位仪记录每个站点的位置.

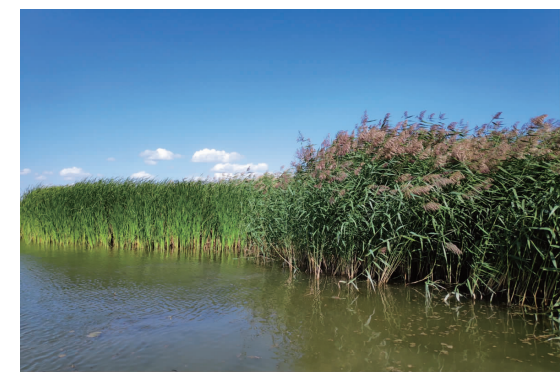

挺水植物

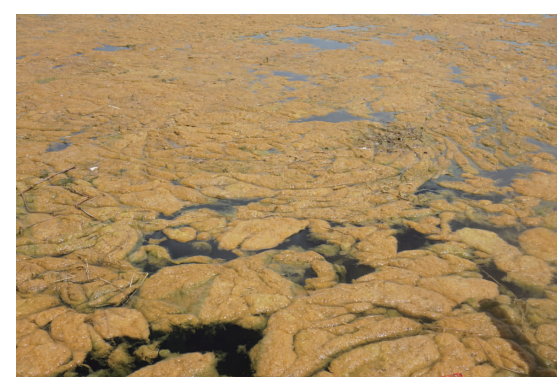

漂浮藻类

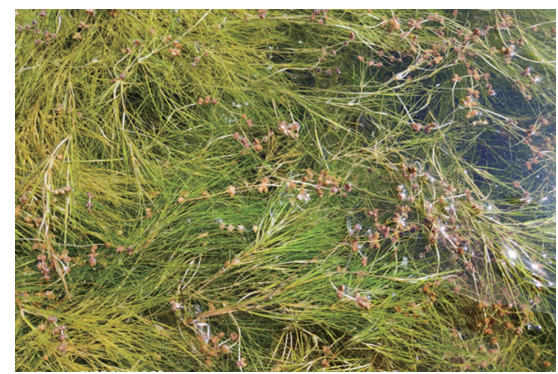

沉水植物

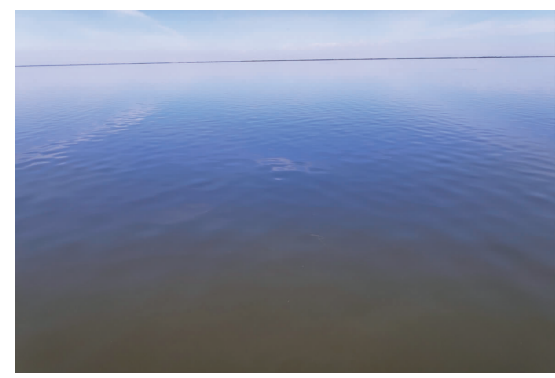

开阔水体

图 2 挺水植物、沉水植物、漂浮藻类、开阔水体照片

Fig.2 Photos of the emergent plants, submerged plants, floating algae and open water

\section{3 遥感影像数据及其预处理}

本文选用 2018 年 9 月 2 日和 2019 年 6 月 17 日的无云覆盖的 2 景 Landsat-8 OLI 影像数据 ( http:// earthexplorer.usgs.gov/). Landsat-8 卫星发射于 2013 年 2 月 11 日, 重访周期为 $16 \mathrm{~d}$, 搭载 2 个传感器, OLI (Operational Land Image) 和 TIRS (Thermal Infrared Sensor). OLI 有 9 个波段,其中全色波段的分辨率为 15 $\mathrm{m}$, 其余 8 个波段的分辨率为 $30 \mathrm{~m}^{[28]}$,9 个波段的中心波长分别为 $443 \mathrm{~nm}$ (Coastal)、 $483 \mathrm{~nm}$ (Blue), $561 \mathrm{~nm}$ (Green)、655 nm(Red)、865 nm(NIR)、1609 nm(SWIR1)、2210 nm(SWIR2)、592 nm(Pan) 和 $1373 \mathrm{~nm}$ (Cirrus). 由于乌梁素海遍布挺水植物、沉水植物、漂浮藻类, 水环境复杂, 精确的气溶胶校正存在困难. 因此 OLI 影像只做了大气瑞利校正, 在此基础上进行 WDC 的遥感反演. 参考 Quinten Vanhellemont \& Kevin Rud$\operatorname{dick}^{[28-29]}$ 进行瑞利校正, 步骤如下:

首先, 利用公式 (1) 进行遥感影像的辐射定标:

$$
L_{\mathrm{TOA}}=M_{L} \cdot D N+A_{L}
$$

式中, $L_{\mathrm{TOA}}$ 为辐射亮度 $\left(\mathrm{W} /\left(\mathrm{m}^{2} \cdot \mu \mathrm{m} \cdot \mathrm{sr}\right)\right), D N$ 值为遥感影像像元亮度值, $M_{L}$ (multiplicative factor, gain) 为增 益系数 $\left(\mathrm{W} /\left(\mathrm{m}^{2} \cdot \mu \mathrm{m} \cdot \mathrm{sr}\right)\right), A_{L}($ additive factor, offset $)$ 为偏移量 $\left(\mathrm{W} /\left(\mathrm{m}^{2} \cdot \mu \mathrm{m} \cdot \mathrm{sr}\right)\right)$, 分别可从 OLI 数据头文件 中获取.

其次,获取大气层顶反射率:

$$
\rho_{\mathrm{TOA}}=\frac{\pi \cdot L_{\mathrm{TOA}} \cdot d^{2}}{F_{0} \cdot \cos \theta_{0}}
$$

式中, $\rho_{\mathrm{TOA}}$ 为大气层顶反射率 $\left(\mathrm{sr}^{-1}\right) ; d$ 为以天文单位表示的日地距离 $(\mathrm{AU}) ; F_{0}$ 为波段平均的大气层外太阳 辐照度 $\left(\mathrm{W} /\left(\mathrm{m}^{2} \cdot \mu \mathrm{m}\right)\right) ; \theta_{0}$ 为太阳高度角 $\left(^{\circ}\right)$. 
大气瑞利校正公式为:

$$
\rho_{\mathrm{r}}=\frac{\tau_{\mathrm{r}} \cdot P_{\mathrm{r}}\left(\theta_{0}, \theta_{\mathrm{v}}, \Delta \varphi\right)}{4 \cos \theta_{0} \cdot \cos \theta_{\mathrm{v}}}
$$

式中, $\rho_{\mathrm{r}}$ 是瑞利反射率 $\left(\mathrm{sr}^{-1}\right) ; \tau_{\mathrm{r}}$ 是瑞利光学厚度 (无单位) ; $P_{\mathrm{r}}$ 是瑞利散射相位函数 $; \theta_{\mathrm{v}}$ 是观测天顶角 $\left({ }^{\circ}\right) ; \Delta \varphi$ 是相对太阳和传感器间高度角 $\left(^{\circ}\right)$.

另外, 本文试图利用瑞利校正后的 OLI 数据进行冠层水深的反演. 因此,利用 OLI 数据的波段响应函 数,将实测光谱反射率积分到 OLI 波段上,波段积分运算见公式 (4) :

$$
R_{\mathrm{rs}}\left(\lambda_{i}\right)=\frac{\sum_{j=1}^{n} F_{i}\left(\lambda_{j}\right) \cdot R_{\mathrm{rs}}\left(\lambda_{j}\right)}{\sum_{j=1}^{n} F_{i}\left(\lambda_{j}\right)}
$$

式中, $R_{\mathrm{rs}}(\lambda)\left(\mathrm{sr}^{-1}\right)$ 表示实测遥感反射率; $F_{i}$ 表示 OLI 数据的第 $i$ 波段的光谱响应函数.

\section{4 方法}

1.4.1 光谱特征分析 基于实测遥感数据, 分析沉水植物与漂浮藻类和挺水植物之间的光谱差异, 辨识沉水 植物与其他水生植物光谱区分特征; 研究沉水植物光谱随冠层深度的变化特征.

1.4.2 相关分析 基于沉水植物光谱特征, 进行冠层水深与沉水植物光谱之间的相关分析, 确定相关性最大 的单波段和波段比. 相关分析同时考虑了皮尔逊(线性)和斯皮尔曼(单调性)相关分析法.

1.4.3 回归模型建立 在 1.4.1 和 1.4.2 工作的基础上,建立单波段/波段比与冠层水深之间的回归模型, 模 型分别为:

$$
\begin{gathered}
W D C=\bar{a} x^{\bar{b}} \\
W D C=\bar{a} \cdot x+\bar{b}
\end{gathered}
$$

式中, $x=R_{\mathrm{r} i \mathrm{i}}$ 或 $R_{\mathrm{ri} i} / R_{\mathrm{rij}}, \bar{a}$ 和 $\bar{b}$ 为模型参数.

采用 $\mathrm{LOOCV}^{[30]}$ 方法确定模型参数 $\bar{a}$ 和 $\bar{b}$, 具体做法如下: 首先剔除第一组样本数据, 其余数据作为训练 样本, 利用最小二乘法确定模型参数; 之后剔除第二组样本数据, 其余数据作为训练样本; 该迭代过程进行 到最后一组样本的剔除为止. 这个过程会产生一系列的模型参数 $a$ 和 $b$, 取其平均值作为模型参数.

1.4.4 精度评估 采用均方根误差 (root mean square error, $R M S E$ ), 平均相对误差 (mean relative percentage error, MRPE) 以及 Pearson 相关系数评价反演模型精度, 计算公式为:

$$
\begin{aligned}
R M S E & =\sqrt{\frac{\sum_{i=1}^{n}\left(x_{\text {imea }}-x_{i \mathrm{pre}}\right)^{2}}{n}} \\
M R P E & =\frac{\sum_{i=1}^{n}\left|\frac{x_{\text {imea }}-x_{\text {ipre }}}{x_{\text {imea }}}\right|}{n} \times 100 \%
\end{aligned}
$$

式中, $x_{i \mathrm{pre}}$ 和 $x_{\text {imea }}$ 分别表示通过模型计算得到的冠层水深和实际测量得到的冠层水深; $n$ 为采样点数.

\section{2 结果}

\section{1 沉水植物与挺水植物和漂浮藻类光谱差异特征}

图 3 为 0 深度沉水植物 ( $W D C=0$ ) 、挺水植物和漂浮藻类实测光谱, 由于 $1349 \sim 1449 、 1750 \sim 1979$ 和 $2350 \sim 2500 \mathrm{~nm}$ 段噪音大, 因此剔除. 由图 3A 可见, 沉水植物 ( WDC $=0$ ) 和挺水植物、漂浮藻类的光谱曲线表 现出典型的植被光谱特征, 在可见光部分的蓝波段 (480 nm 为中心) 和红光波段 (680 $\mathrm{nm}$ 为中心) 附近有较 强的吸收, 形成两个吸收谷, 在 540 560 nm 附近形成了明显的反射绿峰; 在 670 720 nm 之间反射率增高最 快,出现“红边”; 波长 $>700 \mathrm{~nm}$ 时, 其光谱反射率增强,形成了水生植物在近红外波段的高反射区.

三类植物光谱特征差异性表现在: 挺水植物、沉水植物 $(W D C=0)$ 和漂浮藻类在波段 $602 、 1272 、 1662$ 和 $2223 \mathrm{~nm}$ 光谱差异较大 (图 3B). 图 4 和表 1 中对比了挺水植物、沉水植物 ( $W D C=0$ ) 和漂浮藻类在这 4 个特 
征波段处的取值范围. 可以看出, 挺水植物反射率光谱, 在近红外和短波红外波段范围内的 $1272 、 1662$ 和 $2223 \mathrm{~nm}$ 附近分别有一个明显的反射峰, 这是挺水植物区别于沉水植物和漂浮藻类的重要波段. 沉水植物在 近红外高反射率的最大值都在 0.099 以下, 而挺水植物都在 0.152 以上; 漂浮藻类的近红外高反射率在 0.070 0.109 之间, 这与沉水植物的光谱波段有交叉, 变化趋势比较一致, 而且沉水植物和漂浮藻类在 1350 $\mathrm{nm}$ 之后反射率逐渐减少, 均趋于 0 . 虽然沉水植物和漂浮藻类的波谱形状相似, 但是在 $550 \sim 690 \mathrm{~nm}$ 漂浮藻 类的反射率值却高于沉水植物 $(W D C=0)$ 的反射率值, 尤其在 $602 \mathrm{~nm}$ 处漂浮澡类的反射率值最低为 0.046 , 而沉水植物的反射率值最高不到 0.021 . 所以在 $550 \sim 690 \mathrm{~nm}$ 漂浮藻类和沉水植物 ( WDC $=0$ ) 的光谱曲线具 有明显的分层现象,光谱特征差异明显.
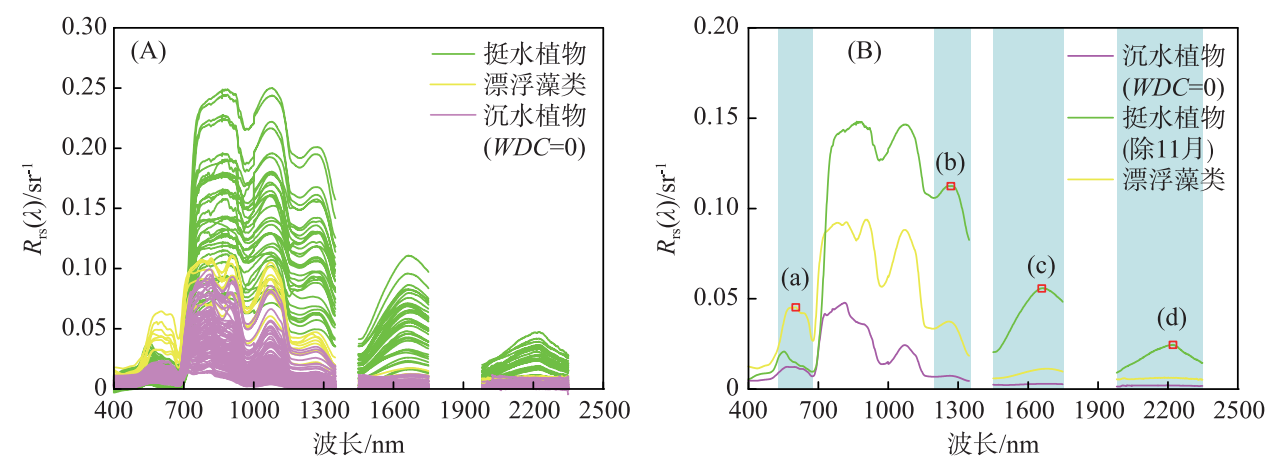

图 3 表层沉水植物、漂浮藻类、挺水植物实测光谱 (a) 和平均光谱 (b) 对比

Fig.3 Contrast of measured (a) and average(b) spectra of surface submerged plants, floating algae and emergent plants
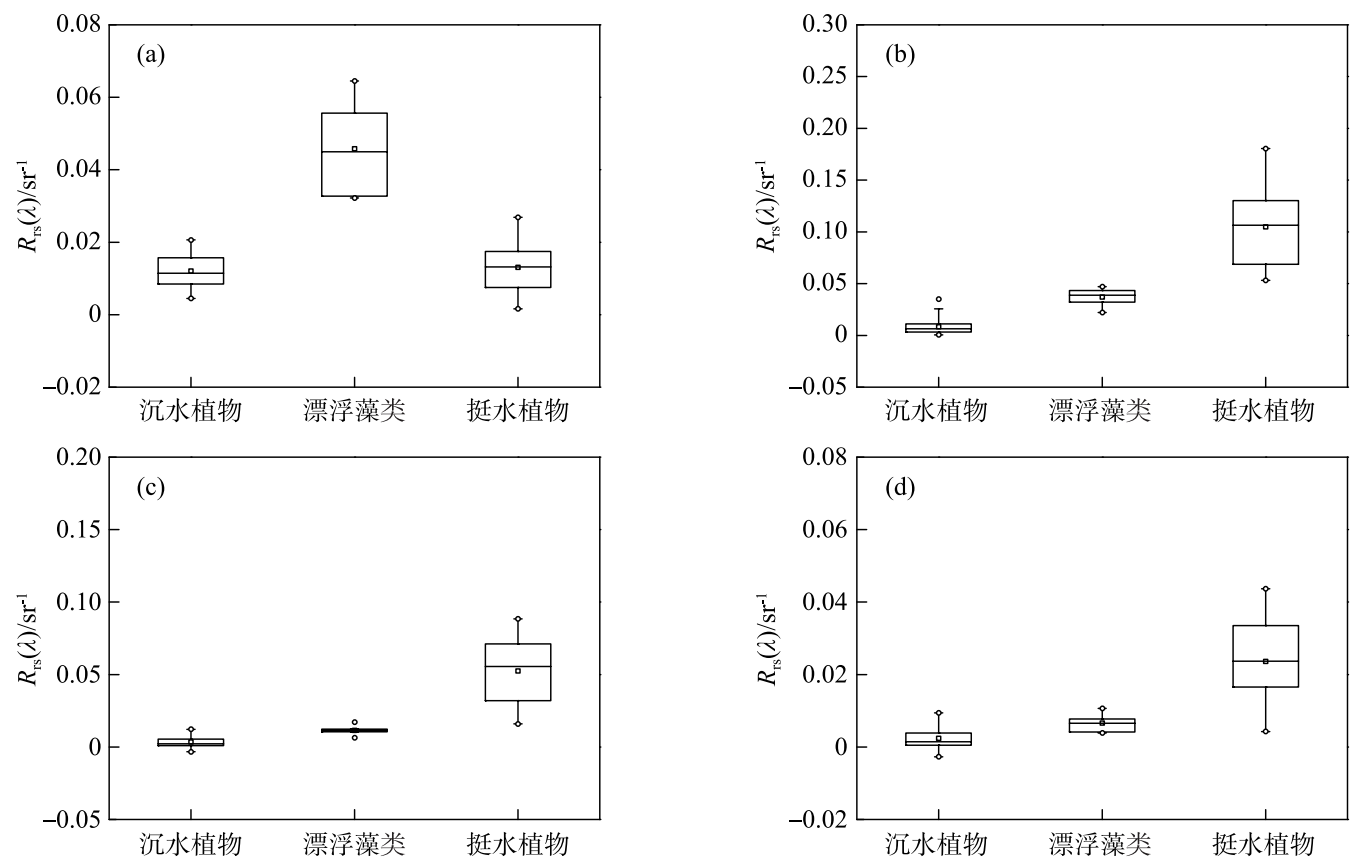

图 4 不同特征波段沉水植物 ( $W D C=0$ ) 、漂浮藻类和挺水植物光谱反射率箱型图: (a) 为 $602 \mathrm{~nm}$ 处; (b) 为 $1272 \mathrm{~nm}$ 处; (c) 为 $1662 \mathrm{~nm}$ 处; (d) 为 $2223 \mathrm{~nm}$ 处

Fig.4 Box charts of submerged plants $(W D C=0)$, floating algae and emergent plants spectral reflectance in different characteristic bands 
表 1 表层沉水植物、漂浮藻类和挺水植物实测光谱参数

Tab.1 Measured spectral parameters of surface submerged plants, floating algae and emergent plants

\begin{tabular}{|c|c|c|c|c|c|c|c|c|c|c|c|c|}
\hline \multirow{2}{*}{ 植物种类 } & \multicolumn{3}{|c|}{$\begin{array}{c}550 \sim 690 \mathrm{~nm} \\
\text { (a) } 602 \mathrm{~nm}\end{array}$} & \multicolumn{3}{|c|}{$\begin{array}{c}1190 \sim 1348 \mathrm{~nm} \\
\text { (b) } 1272 \mathrm{~nm}\end{array}$} & \multicolumn{3}{|c|}{$\begin{array}{c}1450 \sim 1749 \mathrm{~nm} \\
\text { (c) } 1662 \mathrm{~nm}\end{array}$} & \multicolumn{3}{|c|}{$\begin{array}{l}1980 \sim 2349 \mathrm{~nm} \\
\text { (d) } 2223 \mathrm{~nm}\end{array}$} \\
\hline & 最大值 & 最小值 & 平均值 & 最大值 & 最小值 & 平均值 & 最大值 & 最小值 & 平均值 & 最大值 & 最小值 & 平均值 \\
\hline $\begin{array}{l}\text { 沉水植物 } \\
(W D C=0)\end{array}$ & 0.021 & 0.005 & 0.012 & 0.035 & 0.001 & 0.008 & 0.012 & 0.0003 & 0.003 & 0.009 & 0.0002 & 0.002 \\
\hline 漂浮藻类 & 0.060 & 0.032 & 0.046 & 0.047 & 0.022 & 0.037 & 0.017 & 0.006 & 0.012 & 0.011 & 0.004 & 0.007 \\
\hline 挺水植物 & 0.027 & 0.002 & 0.013 & 0.181 & 0.053 & 0.105 & 0.088 & 0.016 & 0.053 & 0.044 & 0.004 & 0.024 \\
\hline
\end{tabular}

\section{2 不同冠层水深的沉水植物光谱特征}

图 5 为不同冠层水深的沉水植物实测光谱曲线. 可以看出, 光谱反射率随冠层水深增加而下降, 在近红 外区域 700 900 $\mathrm{nm}$ 尤为突出, 这是因为水体通过吸收和散射造成的强烈光衰减对沉水植物光谱产生明显
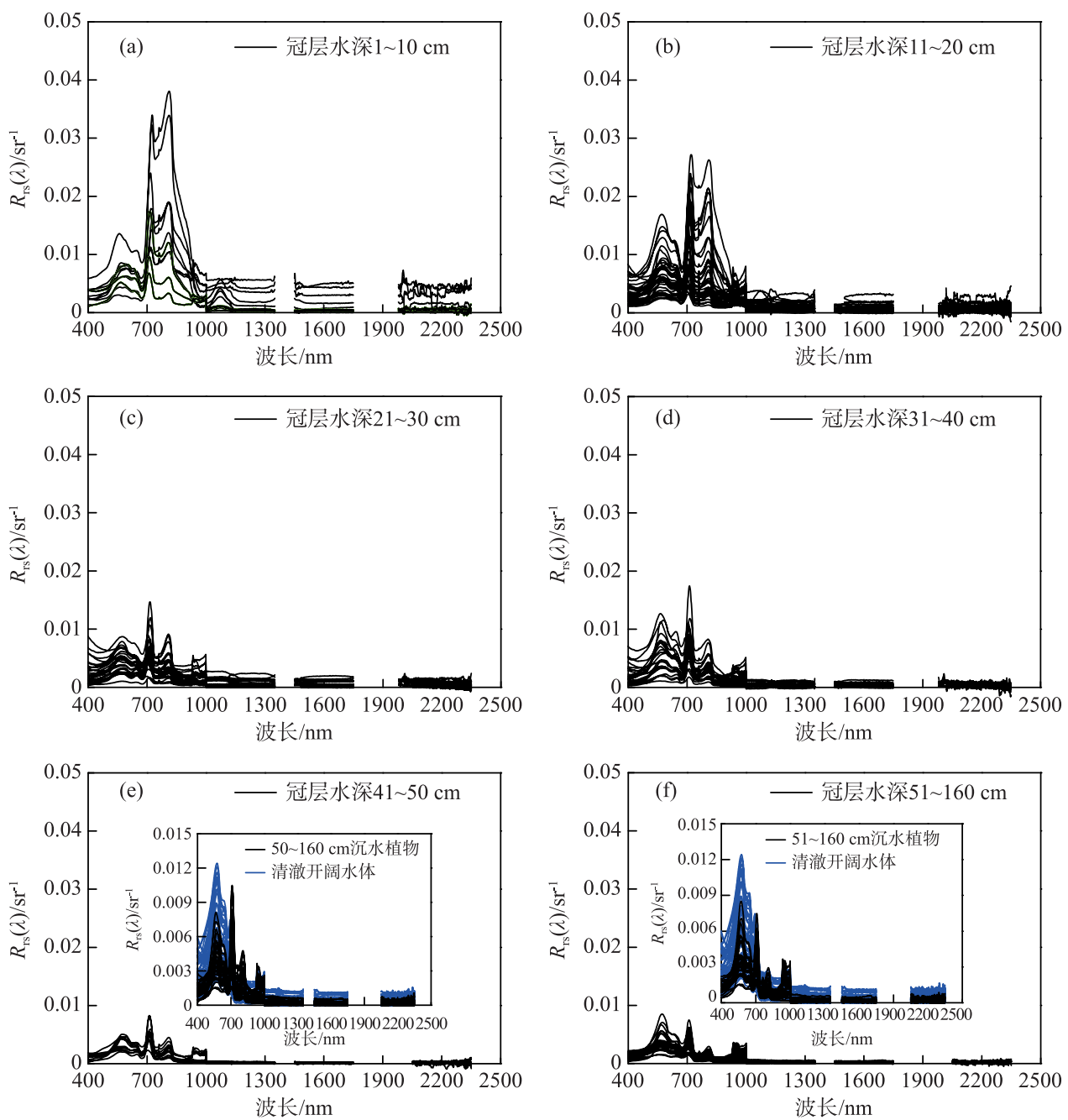

图 5 不同冠层水深沉水植物群落的实测光谱曲线

Fig.5 Measured spectral curves of submerged plant communities in different canopy depths and canopy water depth histogram 
干扰 ${ }^{[16]}$. 随着冠层水深的增加, 沉水植物光谱在 700 $900 \mathrm{~nm}$ 波段范围内出现以 $714 \mathrm{~nm}$ 和 $810 \mathrm{~nm}$ 为中心的 2 个反射峰, 这主要是由于这 2 个波段之间正好是一 个明显的水吸收带 ${ }^{[31]}$. 当冠层离水面的距离为 $50 \mathrm{~cm}$ 时水体与沉水植物群落光谱反射率非常接近, 但在 $810 \mathrm{~nm}$ 处存在细微的差异. 图 6 对比了 $810 \mathrm{~nm}$ 处不 同冠层水深沉水植物和开阔水体的光谱范围. 可以看 出,随着冠层水深的增加,沉水植物反射率的集中区域 逐渐降低变窄,并且逐步趋于 0 , 而且 $51 \sim 160 \mathrm{~cm}$ 深度 范围的沉水植物光谱反射率与开阔水体的光谱反射率 区域非常接近 (图 5e 和图 5f), 这表明冠层水深会影 响沉水植物的光谱反射率.

\section{3 冠层水深反演模型}

2.3.1 冠层水深与沉水植物光谱反射率的相关分析 通过对不同冠层水深的沉水植物光谱特征分析,可以 发现沉水植物群落的光谱反射率随冠层水深的增加而 降低,在 700 900 nm 波段范围内差异最为明显. 由于

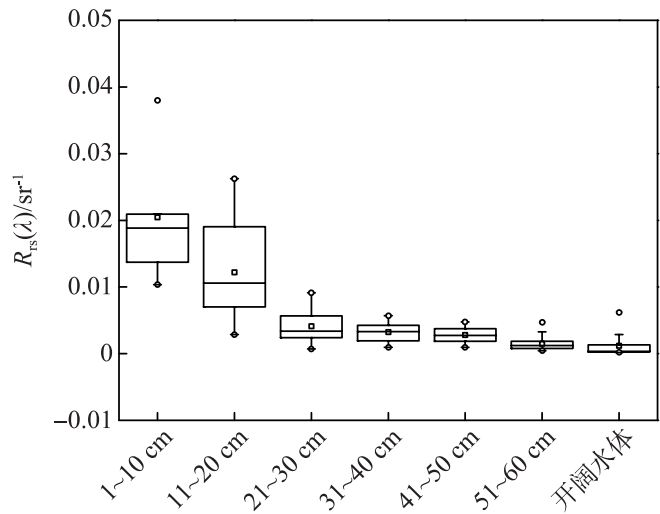

图 $6810 \mathrm{~nm}$ 处不同冠层水深沉水植物和 开阔水体光谱反射率箱型图

Fig. 6 Box chart of submerged plants and open water bodies spectral reflectance with different canopy water depths at $810 \mathrm{~nm}$

乌梁素海各月沉水植物物候特征随季节变化明显,所以分别对 2018 年 7 月、 8 月、 9 月、11月和 2019 年 6 月 沉水植物群落的光谱反射率与冠层水深进行相关性分析 (图 7). 在 700 735 $\mathrm{nm}$ 波段附近, 沉水植物群落光 谱反射率与冠层水深呈显著负相关, 是光谱反射率对冠层水深变化最敏感的波段. 这与 Han 等 ${ }^{[32]}$ 的研究结 果一致. 其中 7 月沉水植物群落的光谱反射率与冠层水深皮尔逊最高的相关系数位于 $715 \mathrm{~nm}$ 处, $r=-0.77$, 斯皮尔曼相关系数为 -0.91 .8 月皮尔逊最高的相关系数位于 $707 \mathrm{~nm}$ 处, $r=-0.75$, 在 $760 \mathrm{~nm}$ 处斯皮尔曼相 关系数最高, $\rho=-0.88 .9$ 月皮尔逊最高的相关系数位于 $719 \mathrm{~nm}$ 处, $r=-0.64$, 在 $819 \mathrm{~nm}$ 处斯皮尔曼相关系 数最高, $\rho=-0.75 .11$ 月皮尔逊最高的相关系数位于 $967 \mathrm{~nm}$ 处, $r=-0.91$, 在 $954 \mathrm{~nm}$ 处斯皮尔曼相关系数最 高, $\rho=-0.98 .2019$ 年 6 月皮尔逊最高的相关系数位于 $715 \mathrm{~nm}$ 处, $r=-0.64$, 在 $733 \mathrm{~nm}$ 处斯皮尔曼相关系数 最高, $\rho=-0.96$. 所有月份的皮尔逊最高的相关系数位于 $720 \mathrm{~nm}$ 处, $r=-0.64$, 在 $733 \mathrm{~nm}$ 处斯皮尔曼相关系 数最高, $\rho=-0.84$. 从 8 月以后的相关性可以看出皮尔逊相关系数与斯皮尔曼相关系数所对应的特征波段差 异很大, 这是因为在 $707 \mathrm{~nm}$ 之后沉水植物光谱反射率与冠层深度可能存在非线性关系. 而且 6、7、8、9 月为 沉水植物群落生长旺季, 沉水植物群落全部呈绿色, 植 株距水面近,近红外光谱反射率最高. 11 月为沉水植 物群落衰退期, 沉水植物群落 “失绿” 呈黄褐色, 植株 距水面远, 沉水植物群落近红外光谱反射率较低. 而 在 700 900 nm 波段附近, 是光谱反射率对冠层水深 变化最敏感的波段,这可能也是影响沉水植物群落与 冠层水深相关性的因素 ${ }^{[33]}$. 通过迭代算法对 $400 \sim$ $1350 \mathrm{~nm}$ (5 nm 间隔)波段区间的实测反射率逐一两两 比值, 与沉水植物群落冠层水深进行相关性计算, 发现 在表 2 波段比处 $r$ 和 $\rho$ 最高.

2.3.2 回归模型通过相关性分析挑选以上单波段/波 段比值为自变量. 利用 $\mathrm{LOOCV}$ 方法确定参数 $\bar{a}$ 和 $\bar{b}$, 建立沉水植物群落的单波段/波段比值的冠层水深遥 感反演模型,模型见表 3.

图 8 为各月单波段/波段比冠层水深反演模型的 实测冠层水深与反演冠层水深对比图, 从图可以看出,

表 2 各月波段比与冠层水深相关系数

Tab. 2 Coefficient of correlation between band ratio and canopy water depth in different months

\begin{tabular}{cccc}
\hline 时间 & 波段比 & $r$ & $\rho$ \\
\hline 2018 年 7月 & $R_{\mathrm{rs}}(685) / R_{\mathrm{rs}}(720)$ & 0.934 & 0.866 \\
& $R_{\mathrm{rs}}(760) / R_{\mathrm{rs}}(825)$ & 0.928 & 0.932 \\
2018 年 8月 & $R_{\mathrm{rs}}(430) / R_{\mathrm{rs}}(900)$ & 0.876 & 0.868 \\
& $R_{\mathrm{rs}}(465) / R_{\mathrm{rs}}(900)$ & 0.871 & 0.896 \\
2018 年 9 月 & $R_{\mathrm{rs}}(515) / R_{\mathrm{rs}}(730)$ & 0.804 & 0.798 \\
& $R_{\mathrm{rs}}(520) / R_{\mathrm{rs}}(730)$ & 0.792 & 0.811 \\
2018 年 11 月 & $R_{\mathrm{rs}}(710) / R_{\mathrm{rs}}(760)$ & 0.954 & 0.927 \\
& $R_{\mathrm{rs}}(740) / R_{\mathrm{rs}}(765)$ & 0.929 & 0.963 \\
2019 年 6月 & $R_{\mathrm{rs}}(590) / R_{\mathrm{rs}}(730)$ & 0.973 & 0.925 \\
& $R_{\mathrm{rs}}(705) / R_{\mathrm{rs}}(730)$ & 0.901 & 0.958 \\
所有月份 & $R_{\mathrm{rs}}(500) / R_{\mathrm{rs}}(735)$ & 0.838 & 0.831 \\
& $R_{\mathrm{rs}}(515) / R_{\mathrm{rs}}(740)$ & 0.833 & 0.842 \\
\hline
\end{tabular}



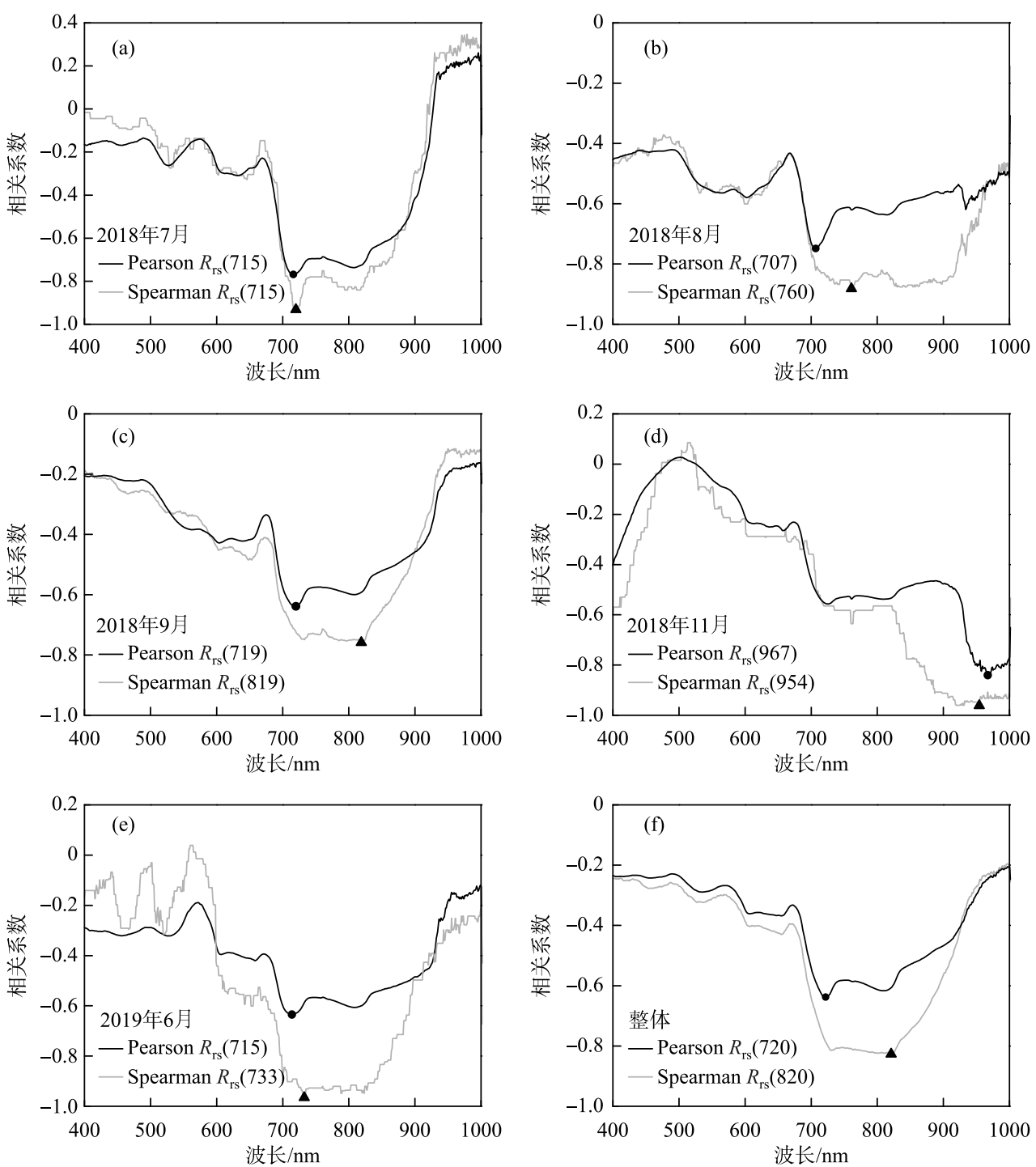

图 7 不同月份沉水植物光谱反射率与冠层水深之间的单波段相关系数

(其中圆点和三角形分别代表皮尔逊和斯皮尔曼相关系数最优的波段位置)

Fig.7 Single band correlation coefficient between spectral reflectance of submerged plants and canopy water depth in different month

波段比的反演精度要高于单波段,这是因为波段比值可在一定程度上消除不同时间和空间上水表面光滑度 和大气对电磁波的影响, 并部分地减少其他物质的干扰 ${ }^{[34]}$, 而单波段却不能. 在单波段的情况下, 幂函数的 反演精度要比线性函数高, 幂函数的决定系数 $R^{2}>0.5$, 均方根误差 $<16.18 \mathrm{~cm}$, 而线性函数的决定系数 $R^{2}>$ 0.4 , 均方根误差 $<18.87 \mathrm{~cm}$, 这是因为在 $700 \sim 735 \mathrm{~nm}$ 波段附近, 沉水植物群落光谱反射率与冠层水深呈显著 负相关,而且在 $707 \mathrm{~nm}$ 之前两者之间的线性关系较好, 在 $707 \mathrm{~nm}$ 之后的近红外波段反射率与冠层水深存在 很好的非线性关系. 在波段比的情况下,幂函数与线性函数的决定系数 $R^{2}$ 非常接近,而且 $R^{2}>0.70$,均方根 误差 $<13.70 \mathrm{~cm} .7$ 月波段比反演模型的线性函数和幂函数的决定系数分别为 0.87 和 0.84 ,均方根误差分别 为 10.39 和 $12.70 \mathrm{~cm}$, 平均相对误差分别为 $22.06 \%$ 和 $22.41 \%$; 8 月波段比的线性函数和幕函数的决定系数 
表 3 单波段/波段比冠层水深反演模型

Tab.3 Single band/band ratio canopy water depth retrieval model

\begin{tabular}{|c|c|c|c|c|c|}
\hline 时间 & 反演方法 & 自变量 & 回归模型 & 模型表达式 & $R^{2}$ \\
\hline \multirow[t]{4}{*}{2018 年 7 月 } & \multirow[t]{2}{*}{ 单波段 } & $R_{\mathrm{rs}}(715)$ & 线性 & $y=-3824.64 x+74.751$ & 0.62 \\
\hline & & $R_{\mathrm{rs}}(715)$ & 幂函数 & $y=0.423 x^{-0.915}$ & 0.69 \\
\hline & \multirow[t]{2}{*}{ 波段比 } & $R_{\mathrm{rs}}(685) / R_{\mathrm{rs}}(720)$ & 线性 & $y=102.785 x-1.887$ & 0.87 \\
\hline & & $R_{\mathrm{rs}}(760) / R_{\mathrm{rs}}(825)$ & 幂函数 & $y=28.380 x^{5.155}$ & 0.84 \\
\hline \multirow[t]{4}{*}{2018 年 8 月 } & \multirow[t]{2}{*}{ 单波段 } & $R_{\mathrm{rs}}(707)$ & 线性 & $y=-3412.007 x+53.715$ & 0.56 \\
\hline & & $R_{\mathrm{rs}}(760)$ & 幂函数 & $y=0.28 x^{-0.806}$ & 0.74 \\
\hline & \multirow[t]{2}{*}{ 波段比 } & $R_{\mathrm{rs}}(430) / R_{\mathrm{rs}}(900)$ & 线性 & $y=17.437 x+2.322$ & 0.79 \\
\hline & & $R_{\mathrm{rs}}(465) / R_{\mathrm{rs}}(900)$ & 幕函数 & $y=15.642 x^{0.927}$ & 0.76 \\
\hline \multirow[t]{4}{*}{2018 年 9 月 } & \multirow[t]{2}{*}{ 单波段 } & $R_{\mathrm{rs}}(719)$ & 线性 & $y=-2576.585 x+67.381$ & 0.46 \\
\hline & & $R_{\mathrm{rs}}(819)$ & 幂函数 & $y=2.430 x^{-0.479}$ & 0.58 \\
\hline & \multirow[t]{2}{*}{ 波段比 } & $R_{\mathrm{rs}}(515) / R_{\mathrm{rs}}(730)$ & 线性 & $y=28.393 x+18.062$ & 0.72 \\
\hline & & $R_{\mathrm{rs}}(520) / R_{\mathrm{rs}}(730)$ & 幂函数 & $y=45.259 x^{0.648}$ & 0.70 \\
\hline \multirow[t]{4}{*}{2018 年 11 月 } & \multirow[t]{2}{*}{ 单波段 } & $R_{\mathrm{rs}}(967)$ & 线性 & $y=-20510.129 x+52.729$ & 0.84 \\
\hline & & $R_{\mathrm{rs}}(954)$ & 幂函数 & $y=0.106 x^{-0.802}$ & 0.82 \\
\hline & \multirow[t]{2}{*}{ 波段比 } & $R_{\mathrm{rs}}(710) / R_{\mathrm{rs}}(760)$ & 线性 & $y=10.209 x+0.855$ & 0.91 \\
\hline & & $R_{\mathrm{rs}}(740) / R_{\mathrm{rs}}(765)$ & 幂函数 & $y=13.351 x^{5.776}$ & 0.80 \\
\hline \multirow[t]{4}{*}{2019 年 6 月 } & \multirow[t]{2}{*}{ 单波段 } & $R_{\mathrm{rs}}(715)$ & 线性 & $y=-4042.927 x+85.839$ & 0.56 \\
\hline & & $R_{\mathrm{rs}}(733)$ & 幂函数 & $y=0.956 x^{-0.653}$ & 0.94 \\
\hline & \multirow[t]{2}{*}{ 波段比 } & $R_{\mathrm{rs}}(590) / R_{\mathrm{rs}}(730)$ & 线性 & $y=11.204 x+14.647$ & 0.95 \\
\hline & & $R_{\mathrm{rs}}(705) / R_{\mathrm{rs}}(730)$ & 幂函数 & $y=15.164 x^{1.170}$ & 0.81 \\
\hline \multirow[t]{4}{*}{ 以上所有月份 } & \multirow[t]{2}{*}{ 单波段 } & $R_{\mathrm{rs}}(720)$ & 线性 & $y=-2502.235 x+62.756$ & 0.46 \\
\hline & & $R_{\mathrm{rs}}(820)$ & 幂函数 & $y=1.131 x^{-0.589}$ & 0.63 \\
\hline & \multirow[t]{2}{*}{ 波段比 } & $R_{\mathrm{rs}}(500) / R_{\mathrm{rs}}(735)$ & 线性 & $y=23.456 x+14.815$ & 0.70 \\
\hline & & $R_{\mathrm{rs}}(515) / R_{\mathrm{rs}}(740)$ & 幂函数 & $y=31.256 x^{0.700}$ & 0.71 \\
\hline
\end{tabular}

分别为 0.79 和 0.76 ,均方根误差分别为 9.23 和 $10.07 \mathrm{~cm}$, 平均相对误差分别为 $36.99 \%$ 和 $36.43 \%$; 9 月波段 比的线性函数和幂函数决定系数分别为 0.72 和 0.70 ,均方根误差分别为 13.36 和 $13.33 \mathrm{~cm}$, 平均相对误差分 别为 $28.75 \%$ 和 $27.06 \% ; 11$ 月波段比的线性函数和幂函数的决定系数分别为 0.91 和 0.80 ,均方根误差分别 为 4.05 和 $5.11 \mathrm{~cm}$, 平均相对误差分别为 $13.55 \%$ 和 $14.75 \%$; 6 月波段比的线性函数和幕函数的决定系数分 别为 0.95 和 0.81 ,均方根误差分别为 6.59 和 $12.40 \mathrm{~cm}$, 平均相对误差分别为 $15.59 \%$ 和 $14.66 \%$; 以上所有月 份波段比的的线性函数和幂函数的决定系数分别为 0.70 和 0.71 ,均方根误差分别为 13.58 和 $13.70 \mathrm{~cm}$,平均 相对误差分别为 $31.42 \%$ 和 $27.57 \%$. 通过各月的 RMSE、MRPE 和散点图可以看出大部分反演值位于 $1: 1$ 线 附近, 与实测值有较好的一致性, 反演精度较高, 单波段模型最好的冠层水深反演精度集中在 $10 \sim 30 \mathrm{~cm}$, 而 波段比模型最好的冠层水深反演精度集中在 10 60 cm.

沉水植物具有净化和改善水质的作用 ${ }^{[17]}$, 通过现场调查发现, 在乌梁素海沉水植物分布区域水体透明 度高, 悬浮物浓度和叶绿素浓度低, 对沉水植物光谱的影响小, 而水面到植物冠层的深度对沉水植物光谱影 响较大,所以本文重点探讨冠层水深对沉水植物光谱的影响.

2.3.3 模型推广 本文试图利用瑞利校正后的 OLI 数据进行冠层水深的反演. 首先, 基于波段响应函数, 将 实测光谱反射率积分到 Landsat-8 OLI 波段上, 见公式 (4) ; 然后, 进行了 OLI 单波段反射率/波段比值与实测 冠层水深之间的相关性分析, 见图 9. OLI 第 5 波段 (中心波段为 $865 \mathrm{~nm}$ ) 的沉水植物光谱反射率与冠层水深 的相关性最大, 其皮尔逊相关系数为 $r=0.54$, 斯皮尔曼相关系数为 $\rho=0.73$. 在波段比 $R_{\mathrm{rs}}($ Costal $) / R_{\mathrm{rs}}(\mathrm{NIR})$ 处沉水植物光谱反射率与冠层水深的皮尔逊相关系数最大, $r=0.67$. 在波段比 $R_{\mathrm{rs}}(\mathrm{Blue}) / R_{\mathrm{rs}}(\mathrm{NIR})$ 处斯皮尔 曼相关系数最大, $\rho=0.76$. 这是因为植物的叶绿素对蓝光的强吸收和对近红外波段 ( $850 \sim 880 \mathrm{~nm}$ ) 高反射导 

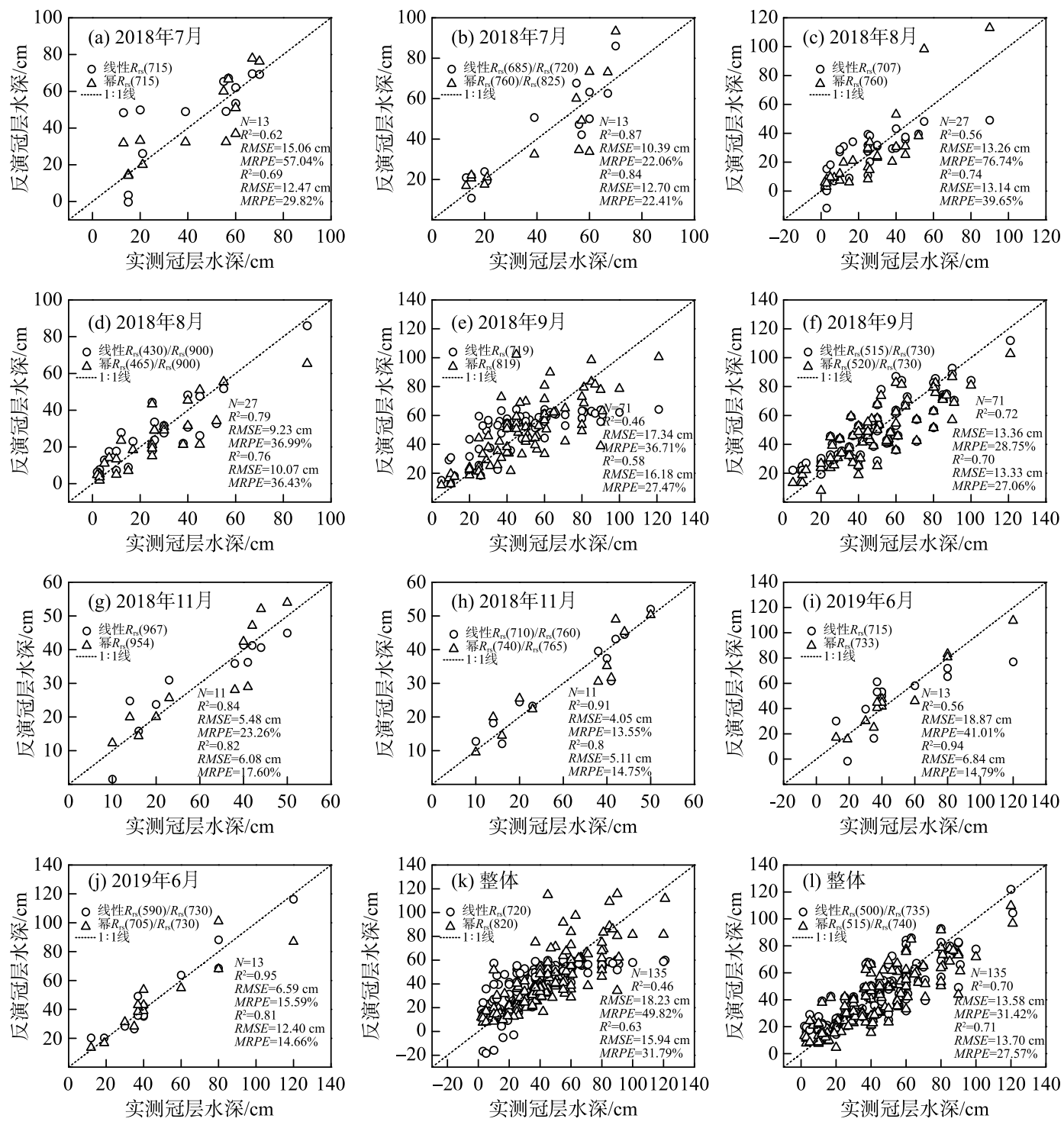

图 8 各月冠层水深实测值与反演值对比

Fig.8 Comparison of estimated values and measured values of canopy water depth in different months

致的 ${ }^{[35-37]}$. 因此, 将 $R_{\mathrm{rs}}($ Costal $) / R_{\mathrm{rs}}(\mathrm{NIR})$ 和 $R_{\mathrm{rs}}(\mathrm{Blue}) / R_{\mathrm{rs}}(\mathrm{NIR})$ 作为自变量, 利用 LOOCV 方法建立 OLI 波 段比的冠层水深反演模型, 其中以 $R_{\mathrm{rs}}(\mathrm{Costal}) / R_{\mathrm{rs}}(\mathrm{NIR})$ 为自变量的波段比线性函数模型为 $y=14.295 x+$ $17.534, R^{2}=0.44$, 以 $R_{\mathrm{rs}}$ ( Blue $) / R_{\mathrm{rs}}$ ( NIR) 作为自变量的波段比幂函数模型为 $y=23.845 x^{0.716}, R^{2}=0.49$.

图 10 为 OLI 冠层水深反演值与实测值对比图. 由图 10 可知, OLI 冠层水深反演结果与实测值之间有良 好的一致性, 其中波段比的幂函数反演结果最好. 波段比的线性反演模型的决定系数 $R^{2}$ 为 0.44 , 均方根误差 为 $18.60 \mathrm{~cm}$, 平均相对误差为 $63.67 \%$, 幂函数反演模型的决定系数 $R^{2}$ 为 0.49 , 均方根误差为 $18.17 \mathrm{~cm}$, 平均 相对误差为 $40.05 \%$. 通过 135 个 RMSE、MRPE 和散点图 10 可以看出大部分反演的冠层水深位于 $1: 1$ 线附 近, 表明本文使用的 Landsat-8 OLI 幂函数反演模型获得了较好的结果.

2.3.4 Landsat-8 OLI 波段比模型反演乌梁素海冠层水深 将 OLI 波段比幂函数模型应用于瑞利校正后的 OLI 影像 (2018 年 9 月 2 日和 2019 年 6 月 17 日), 图 11 对比了 OLI 反演的冠层水深和实测值. 从散点图可 

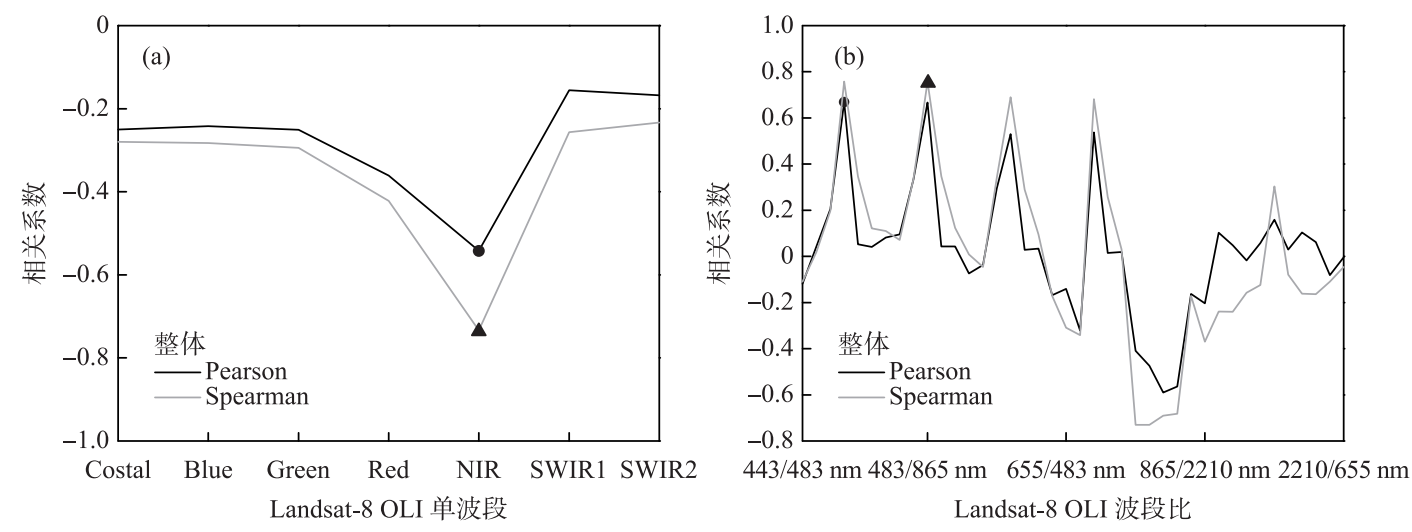

图 9 Landsat-8 OLI 单波段、波段比沉水植物光谱反射率与冠层水深的相关系数:

(a) 为单波段, (b) 为波段比(其中圆点和三角形分别代表皮尔逊和斯皮尔曼相关系数最优的波段位置)

Fig.9 Correlation coefficient between spectral reflectance of submerged plants and canopy water depth in single band (a), band ratio (b) of Landsat-8 OLI

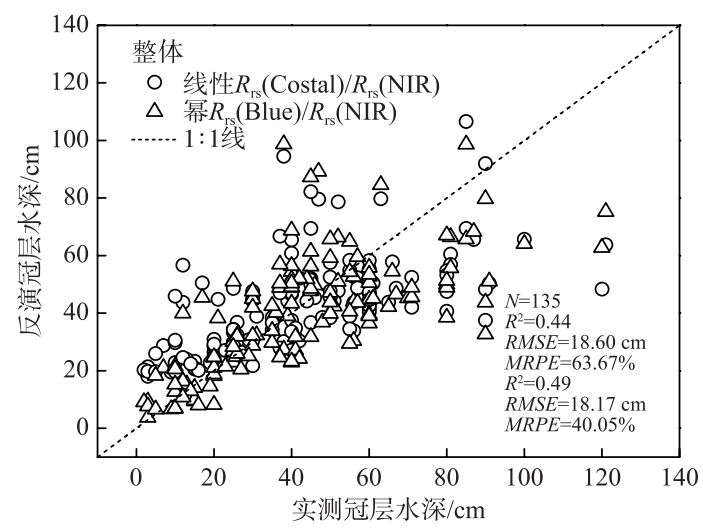

图 10 Landsat-8 OLI 冠层水深反演值与实测值对比

Fig.10 Comparison of estimated values and measured values of canopy water depth in Landsat-8 OLI

以看出, 反演冠层水深和实测冠层水深具有较好的一致性, $R^{2}$ 为 0.67 . 然而, OLI 数据只做了瑞利校正, 未做 气溶胶校正,因此反演冠层水深与实测值之间存在一定的偏差.

因此, 以瑞利校正后 Landsat-8 OLI 的 Band $2 /$ Band 5 反射率为自变量建立了冠层水深反演模型, 模型为 $y=57.68 x^{0.98}, R^{2}=0.70$. 图 12 中对比了大气瑞利校正后 Landsat-8 OLI 影像数据波段比模型反演得到的冠层 水深和实测值. 由图 12 可以看出冠层水深散点大部分都位于 $1: 1$ 线附近, $R^{2}$ 为 $0.70, R M S E$ 为 $22.34 \mathrm{~cm}$, $M R P E$ 为 $38.66 \%$. 因此利用此模型得到了 2018 年 9 月 2 日和 2019 年 6 月 17 日乌梁素海沉水植物冠层水深 分布图, 见图 13. 由图 13 可以看出, 6 月与 9 月沉水植物冠层水深差异明显, 从整体来看, 9 月中部和东部的 沉水植物冠层水深较小, 而 6 月较大, 这是因为 9 月沉水植物仍为生长旺季, 植株距水面近, 而 6 月沉水植物 刚刚进人生长旺季, 植株距水面较远. 从局部来看, 9 月北部沉水植物冠层水深较大, 而 6 月却较小; 中部 9 月沉水植物平均冠层水深较小, 而 6 月平均冠层水深较大; 东部 9 月沉水植物冠层水深较小, 而 6 月冠层水 深较大. 这种冠层水深空间分布特征与现场船舶走航观测结果大体一致. 


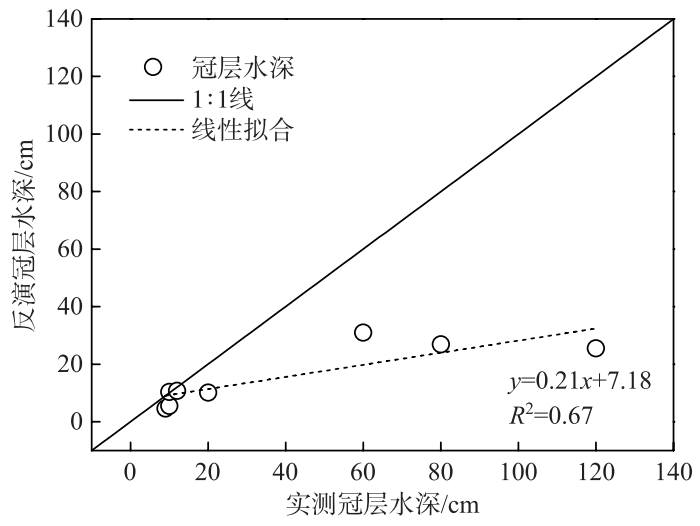

图 11 Landsat-8 OLI 影像数据波段比幂函数模型 反演冠层水深的反演值与实测值对比

Fig.11 Comparison of estimated values and measured values of canopy water depth by band ratio power

function model of Landsat-8 OLI image data

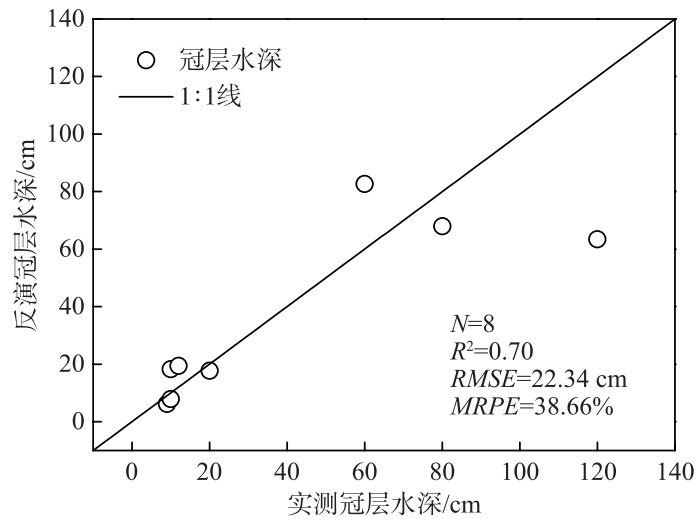

图 12 大气瑞利校正后 Landsat-8 OLI 影像数据波段 比模型反演冠层水深的反演值与实测值对比

Fig. 12 Comparison of estimated values and measured values of canopy water depth by band ratio model of Landsat-8 OLI image data after atmospheric Rayleigh correction

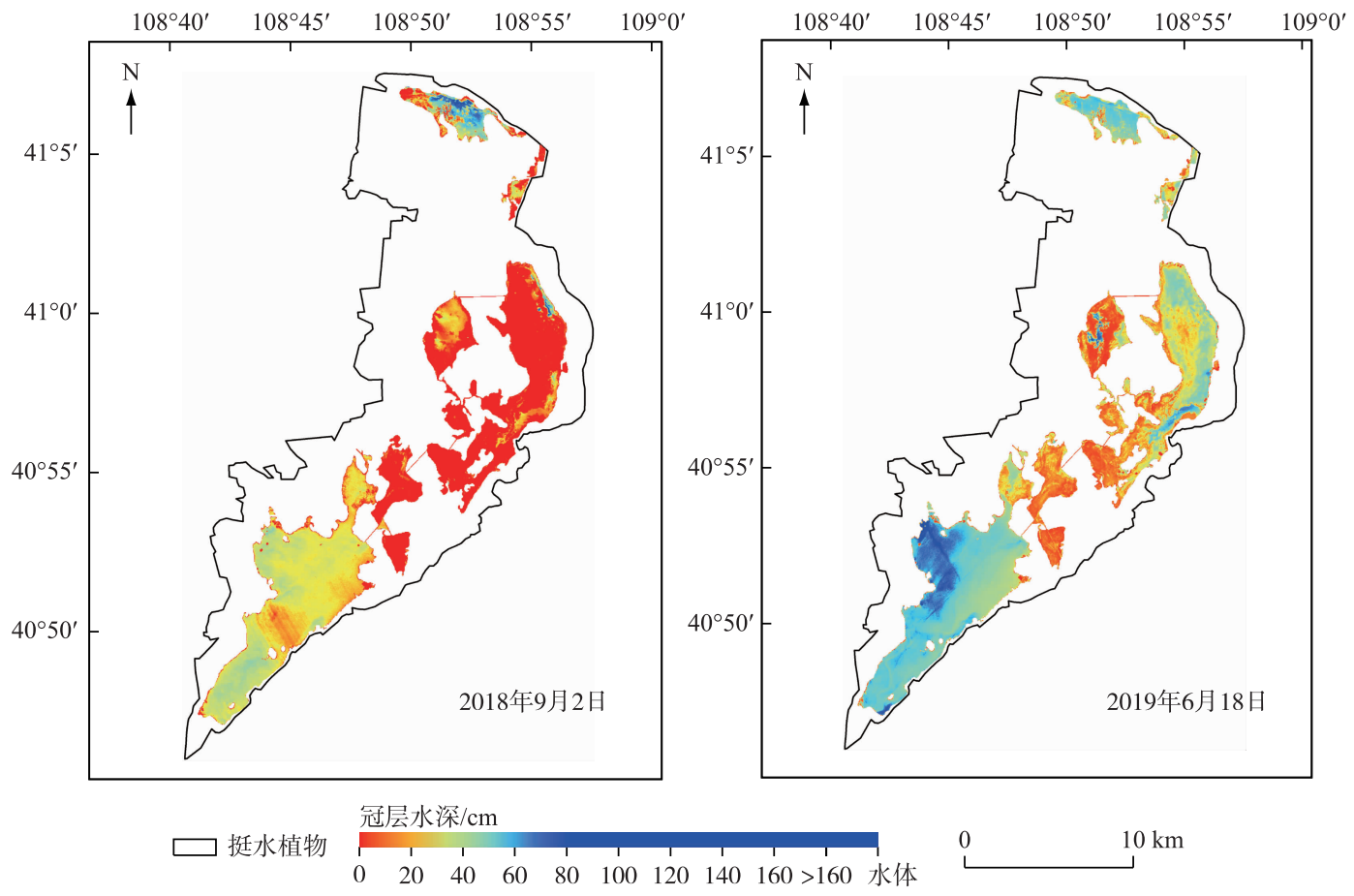

图 13 乌梁素海沉水植物冠层水深分布 (手动提取了挺水植物)

Fig.13 Canopy water depth distribution of submerged plants in Lake Ulansuhai

\section{3 讨论与结论}

本文利用实测水生植物遥感光谱数据, 分析了沉水植物与挺水植物和漂浮藻类光谱特征差异及沉水植 物光谱随冠层水深的变化特征,得出以下结论: 
1) 沉水植物和漂浮藻类在可见光和近红外的光谱反射率明显低于挺水植物; 挺水植物在短波红外 1662 $\mathrm{nm}$ 和 $2223 \mathrm{~nm}$ 附近分别有一个反射峰, 这是挺水植物区别于沉水植物和漂浮藻类的重要波段. 0 深度沉水 植物 $(W D C=0)$ 与漂浮藻类的光谱反射率非常接近, 但是在 $550 \sim 690 \mathrm{~nm}$ 有明显差异, 漂浮藻类的反射绿峰 要高于沉水植物,并具有明显分层现象. 因此,可以利用绿波段和短波红外波段的光谱特征来区分挺水植 物、沉水植物和漂浮藻类.

2) 沉水植物群落的光谱反射率随冠层水深的增加而降低, 在 700 900 nm 波段范围内变化最为明显, 且 在 700 735 nm 波段附近, 沉水植物群落光谱反射率与冠层水深呈显著负相关. 8 月以后的 $r$ 与 $\rho$ 所对应的 特征波段差异很大, 在 $707 \mathrm{~nm}$ 之前沉水植物群落光谱反射率与冠层水深的线性关系较好, 在 $707 \mathrm{~nm}$ 之后两 者存在很好的非线性关系.

3) 利用 LOOCV 方法, 以单波段/波段比为自变量建立了沉水植物群落冠层水深反演模型, 其中波段比 反演模型要优于单波段反演模型, 波段比反演模型的决定系数 $R^{2}>0.70$, 均方根误差 $<13.70 \mathrm{~cm}$, 平均相对误 差 $<28 \%$. 反演精度较好, 适用于 10 60 $\mathrm{cm}$ 沉水植物冠层水深的反演. 利用冠层水深与湖水深度, 可以绘制 沉水植物高度图, 与覆盖度相结合可以估算沉水植物生物量, 该模型可以有效地推导出冠层水深, 这可以为 遥感研究沉水植物提供有效依的科学依据.

4) 利用波段积分运算将实测光谱反射率扩展应用到 Landsat-8 OLI 波段上,建立了 OLI 单波段/波段比 冠层水深反演模型, 其中波段比幂函数反演模型效果最好, 其决定系数 $R^{2}$ 为 0.49 , 均方根误差为 $18.17 \mathrm{~cm}$, 平均相对误差为 $40.05 \%$. 利用大气瑞利校正后 Landsat-8 OLI 影像数据波段比模型得到了 2018 年 9 月 2 日 和 2019 年 6 月 17 日乌梁素海沉水植物冠层水深分布图. OLI 遥感反演的冠层水深具有一定的不确定性, 原 因主要为: 1 ) 实测点位与遥感数据空间尺度不一致. 现场实测为点位数据, 而 OLI 为面数据 (空间分辨率 30 $\mathrm{m} \times 30 \mathrm{~m}$ ), 在 $900 \mathrm{~m}^{2}$ 内乌梁素海沉水植物水深不均一, 这是造成反演结果存在误差的重要原因. 2) 由于乌梁 素海水环境复杂, 精确的大气校正实现困难, 本文所用的 OLI 数据只做了瑞利校正, 未做气溶胶校正, 这也 是导致反演误差的重要因素之一. 因此, 在以后的研究中可以结合无人机高光谱对乌梁素海沉水植物冠层 水深的遥感反演模型进行验证.

\section{4 参考文献}

[ 1 ] Wang WH, Ji M. Ecological character of submerged macrophyte Ruppia maritime. Land its response to environmental changes. Marine Science Bulletin, 2006, 25(3) : 13-22. [王卫红, 季民. 沉水植物川蔓藻的生态学特征及其对环境变化 的响应. 海洋通报, 2006, 25(3): 13-22.]

[ 2 ] Blindow I, Hargeby A, Andersson G. Seasonal changes of mechanisms maintaining clear water in a shallow lake with abundant Chara vegetation. Aquatic Botany, 2002, 72(3/4) : 315-334.

[ 3 ] Tong CH, Yang XE, Pu PM. Purification of eutrophication water by aquatic plant. Chinese Journal of Applied Ecology, 2004, 15(8): 1447-1450. [童昌华, 杨肖娥, 兴培民. 富营养化水体的水生植物净化试验研究. 应用生态学报, 2004, 15(8): 1447-1450.]

[ 4 ] Barillé L, Robin M, Harin N et al. Increase in seagrass distribution at Bourgneuf Bay (France) detected by spatial remote sensing. Aquatic Botany, 2009, 92(3): 185-194.

[ 5 ] Wang Q, Zhou XD, Luo JH et al. Remote sensing monitoring and analysis of dominant species of submerged vegetation in Taihu Lake over last 30 years. Water Resources Protection, 2016, 32 (5): 123-129, 135. [王琪, 周兴东, 罗菊花等. 近 30 年太湖沉水植物优势种遥感监测及变化分析. 水资源保护, 2016, 32 (5) : 123-129, 135.]

[ 6 ] Chen Q, Yu R, Hao Y et al. A new method for mapping aquatic vegetation especially underwater vegetation in Lake Ulansuhai using GF-1 Satellite Data. Remote Sensing, 2018, 10(8) : 1-16.

[ 7 ] Luo JH, Duan HT, Ma RH et al. Mapping species of submerged aquatic vegetation with multi-seasonal satellite images and considering life history information. International Journal of Applied Earth Observations and Geoinformation, 2017, 57: 154-165.

[ 8 ] Brooks C, Grimm A, Shuchman R et al. A satellite-based multi-temporal assessment of the extent of nuisance Cladophora and related submerged aquatic vegetation for the Laurentian Great Lakes. Remote Sensing of Environment, 2015, 157 : 58-71. 
[ 9 ] Lin C, Gong ZN, Zhao WJ. The extraction of wetland hydrophytes types based on medium resolution TM data. Acta Ecologica Sinica, 2010, 30(23) : 6460-6469. [林川, 宫兆宁, 赵文吉. 基于中分辨率 TM 数据的湿地水生植被提取. 生态 学报, $2010,30(23): 6460-6469$. ]

[10] Rotta LHS, Deepak R, Mishra D et al. Analyzing the feasibility of a space-borne sensor (SPOT-6) to estimate the height of submerged aquatic vegetation (SAV) in inland waters. ISPRS Journal of Photogrammetry and Remote Sensing, 2018, 144: 341-356.

[11] Zhang Q, Zheng YQ. Hyperspectral remote sensing and its development and application review. Optics \& Optoelectronic Technology, 2013, 11(3) : 67-73. [张达, 郑玉权. 高光谱遥感的发展与应用. 光学与光电技术, 2013, 11(3): 67-73. ]

[12] William DJ, Rybicki NB, Lombana AV et al. Preliminary investigation of submerged aquatic vegetation mapping using hyperspectral remote sensing. Environmental Monitoring and Assessment, 2003, 81(1/2/3) : 383-392.

[13] Hestir EL, Khanna S, Andrew ME et al. Identification of invasive vegetation using hyperspectral remote sensing in the California Delta ecosystem. Remote Sensing of Environment, 2008, 112(11) : 4034-4047.

[14] Pande-Chhetri R, Abd-Elrahman A, Jacoby C. Classification of submerged aquatic vegetation in black river using hyperspectral image analysis. Geomatica, 2014, 68(3) : 169-182.

[15] Zou WN, Yuan L, Zhang LQ. Analyzing the spectral response of submerged aquatic vegetation in a eutrophic lake, Shanghai, China. Ecological Engineering, 2013, 57: 65-71.

[16] Visser F, Wallis C, Sinnott AM. Optical remote sensing of submerged aquatic vegetation: Opportunities for shallow clearwater streams. Limnologica - Ecology and Management of Inland Waters, 2013, 43( 5) : 388-398. DOI: 10.1016/j.limno. 2013.05005 .

[17] Brooks C, Grimm A, Shuchman R et al. A satellite-based multi-temporal assessment of the extent of nuisance Cladophora and related submerged aquatic vegetation for the Laurentian Great Lakes. Remote Sensing of Environment, 2015, 157: 58-71.

[18] Stratoulias D, Balzter H, Zlinszky A et al. Assessment of ecophysiology of lake shore reed vegetation based on chlorophyll fluorescence, field spectroscopy and hyperspectral airborne imagery. Remote Sensing of Environment, 2015, 157: 72-84.

[19] Wang Q, Zhou XD, Luo JH et al. Remote sensing monitoring and analysis of dominant species of submerged vegetation in Taihu Lake over last 30 years. Water Resources Protection, 2016, 32 (5) : 123-129, 135. [王琪, 周兴东, 罗菊花等. 近 30 年太湖沉水植物优势种遥感监测及变化分析. 水资源保护, 2016, 32(5): 123-129, 135.$]$

[20] Zhang Y. Mechanism of pollutant migration during icing process in Ulansuhai and its application[Dissertation]. Hohhot: Inner Mongolia Agricultural University, 2012. [张岩. 乌梁素海结冰过程中污染物迁移机理及其应用研究 [ 学位论 文]. 呼和浩特: 内蒙古农业大学, 2012.]

[21] Yu LH, Zhang XY, Li WP et al. Characteristics of planktonic algal community in winter in Lake Wuliangsuhai. Environmental Engineering, 2014, 32(3) : 43-47. [于玲红, 张晓雅, 李卫平等. 冬季乌梁素海浮游藻类群落结构特征. 环 境工程, 2014, 32(3): 43-47.]

[22] Yu RH, Li CY, Liu TX et al. Change of wetland environment in Wuliangsuhai. Acta Geographica Sinica, 2004,59 (6) : 948-955. [于瑞宏, 李畅游, 刘廷坌等.乌梁素海湿地环境的演变. 地理学报, 2004, 59(6) : 948-955.]

[23] Li JR, Li X. Application of self-organizing map to analysis of phytoplankton community structure in Wuliangsuhai Lake, China. Ecology and Environmental Sciences, 2017, 26 (4) : 649-657. [李建茹, 李兴. 基于 SOM 的乌梁素海浮游植物 群落结构研究. 生态环境学报, 2017, 26 (4) : 649-657.]

[24] Yue D, Liu DW, Wang LX et al. Change of vegetation cover based on NDVI at Wuliangsu Lake Wetland. Arid Zone Research, 2015, 32 (2) : 266-271. [岳丹, 刘东伟, 王立新等. 基于 NDVI 的乌梁素海湿地植被变化. 干旱区研究, $2015,32(2): 266-271$.

[25] Bao H, Zhuo Y, Liu HM et al. Estimation of RS-based biomass of Phragmites communis in wetland of the Lake Ulansuhai. Arid Zone Research, 2016, 33 (5) : 1028-1035. [包菡, 卓义, 刘华民等. 乌梁素海芦苇湿地遥感生物量估算研究. 干旱区研究, 2016, 33 (5) : 1028-1035. ]

[26] Zheng W, Han XZ, Liu C et al. Satellite remote sensing data monitoring " Huang Tai" algae bloom in Lake Ulansuhai, Inner Mongolia. J Lake Sci, 2010, 22(3) : 321-326. DOI: 10.18307/2010.0303. [郑伟, 韩秀珍, 刘诚等. 内蒙古乌梁 素海“黄苔”暴发卫星遥感动态监测. 湖泊科学, 2010, 22 (3) : 321-326.] 
[27] Tang JW, Tian GL, Wang XY et al. The methods of water spectra measurement and analysis I : Above-water method. Journal of Remote Sensing, 2004, (1):37-44. [唐军武, 田国良, 汪小勇等. 水体光谱测量与分析 I : 水面以上测量 法. 遥感学报, 2004, (1): 37-44.]

[28] Vanhellemont Q, Ruddick K. Turbid wakes associated with offshore wind turbines observed with Landsat 8. Remote Sensing of Environment, 2014, 145(4) : 105-115.

[29] Vanhellemont Q, Ruddick K. Advantages of high quality SWIR bands for ocean colour processing: Examples from Landsat8. Remote Sensing of Environment, 2015, 161(5) : 89-106.

[30] Wang JJ, Lu XX, Liew SC et al. Remote sensing of suspended sediment concentrations of large rivers using multi-temporal MODIS images: an example in the Middle and Lower Yangtze River, China. International Journal of Remote Sensing, 2010, 31(4) : 1131-1138.

[31] Zhao YS ed. Principle and method of remote sensing applied analysis. Beijing: Science Press, 2003: 397. [赵英时. 遥感 应用分析原理与方法. 北京: 科学出版社, 2003: 397.]

[32] Han L, Rundquist DC. The spectral responses of Ceratophyllum demersum at varying depths in an experimental tank. International Journal of Remote Sensing, 2003, 24(4) : 859-864.

[33] Zou WN, Yuan L, Zhang LQ et al. Impacts of coverage and canopy water depth on the spectral characteristics for a submerged plant Cabomba caroliniana. Acta Ecologica Sinica, 2012, 32(3): 706-714. [邹维娜, 袁琳, 张利权等. 盖度与 冠层水深对沉水植物水盾草光谱特性的影响. 生态学报, 2012, 32(3) : 706-714.]

[34] Pan YY, Guo QZ, Fu Y. Study on the inversion of suspended solids concentration in Haihe River based on the measured spectra. Environmental Monitoring in China, 2018, 34(3): 148-154. [潘应阳, 国巧真, 付盈. 基于实测光谱的海河 悬浮物浓度反演研究. 中国环境监测, 2018, 34(3): 148-154.]

[35] Mishra DR, Mishra S. Plume and bloom: effect of the Mississippi River diversionon the water quality of Lake Pontchartrain. Geocarto Int, 2010, 25 ( 7) : 555-568.

[36] Jensen JR. An earth resource perspective. Translated by Epiphanio ( Coord.). Sensoriamento remoto do ambiente-uma perspectiva em recursos terrestres. São José dos. Parêntese, Campos, SP. Remote Sensing of the Environment, 2009.

[37] Jordan CF. Derivation of leaf-area index from quality of light on the forest floor. Ecology, 1969, 50(4) : 663-666. 